\title{
Utility of ultrasound assessment of diaphragmatic function before and after pulmonary rehabilitation in COPD patients
}

This article was published in the following Dove Press journal: International Journal of COPD

\author{
Claudia Crimi ${ }^{1}$ \\ Enrico Heffler ${ }^{2}$ \\ Teresa Augelletti ${ }^{2}$ \\ Raffaele Campisi' \\ Alberto Noto ${ }^{3}$ \\ Carlo Vancheri ${ }^{4}$ \\ Nunzio Crimi ${ }^{2}$ \\ 'Respiratory Medicine Unit, AOU \\ "Policlinico-Vittorio Emanuele", \\ Catania, Italy; ${ }^{2}$ Respiratory Medicine \\ Unit, Department of Clinical and \\ Experimental Medicine, $\mathrm{AOU}$ \\ "Policlinico-Vittorio Emanuele", \\ University of Catania, Catania, Italy; \\ ${ }^{3}$ Anesthesia and Intensive Care \\ Unit, AOU Policinico "G. Martino", \\ Messina, Italy; ${ }^{4}$ Regional Referral \\ Centre for Rare Lung Diseases, A.O.U. \\ "Policlinico-Vittorio Emanuele", \\ Department of Clinical and \\ Experimental Medicine, University \\ of Catania, Catania, Italy
}

Background: Pulmonary rehabilitation (PR) may improve respiratory symptoms and skeletal muscle strength in patients with COPD. We aimed to evaluate changes in ultrasound (US) measurements of diaphragmatic mobility and thickness after PR in COPD patients and to test its correlation with PR outcomes.

Methods: Twenty-five COPD patients were enrolled and underwent a diaphragm US assessment before and after a 12-week PR program.

Results: We found a correlation between the intraindividual percentage of change in the diaphragmatic length of zone of apposition at functional residual capacity ( $\Delta$ Lzapp $\%$ ) and the change in 6-minute walking distance (6MWD) after PR (rho=0.49, $P=0.02) . \Delta$ Lzapp\% was significantly higher in patients with improved 6MWD and COPD Assessment Test (CAT) score (mean rank $=12.03 \pm 2.57$ vs $6.88 \pm 4.37 ; P=0.02$ ). A $\Delta \mathrm{Lzapp} \%$ of $\geq 10 \%$ was able to discriminate among patients with improved 6MWD, with a sensitivity of $83 \%$ and a specificity of $74 \%$. The area under the receiver operating characteristic curve for $\Delta \mathrm{Lzapp} \%$ was 0.83 . A cutoff value of $\geq 9 \%$ of $\Delta \mathrm{Lzapp} \%$ had a positive predictive value in discriminating a reduction in $\geq 2$ points of CAT score after PR, with a sensitivity and a specificity of $80 \%$ and $62 \%$, respectively.

Conclusion: Diaphragm US assessment represents a useful prognostic marker of PR outcomes in COPD patients.

Keywords: diaphragm ultrasound, COPD, pulmonary rehabilitation

\section{Introduction}

Pulmonary rehabilitation (PR) is a well-recognized intervention in the management of individuals with COPD that is designed to improve patients' physical and psychosocial conditions by providing tailored interventions including exercise training, education, and behavioral changes given by an interdisciplinary team of healthcare professionals. $^{1}$

There is strong evidence that exercise training lessens ventilatory requirement and reduces the degree of dynamic lung hyperinflation leading to improved arterial oxygen content and central hemodynamic responses, thus increasing systemic muscle oxygen availability. ${ }^{2}$ In previous studies, it has been shown that the combination of improved mechanical efficiency and improved respiratory and skeletal muscle strength $^{3}$ may determine desensitization to dyspnea ${ }^{4}$ and consequently reduce dynamic hyperinflation. $^{2}$

These physiological benefits apply to all COPD patients, irrespective of the degree of disease severity, ${ }^{5}$ and are associated with improved exercise tolerance, functional capacity, and quality of life ${ }^{6}$ thereby reducing breathlessness and hospital admissions
Correspondence: Claudia Crimi

Respiratory Medicine Unit, A.O.U.

"Policlinico-Vittorio Emanuele", Via S.

Sofia, 78, 95123 , Catania, Italy

$\mathrm{Tel}+3995378 \mid 423$

Fax $+3995378 \quad 1423$

Email dott.claudiacrimi@gmail.com hereby accept the Terms. Non-commercial uses of the work are permitted without any further permission from Dove Medical Press Limited, provided the work is properly attributed. For permission for commercial use of this work, please see paragraphs 4.2 and 5 of our Terms (https://www.dovepress.com/terms.php). 
and improving recovery after exacerbation. ${ }^{1}$ However, the responses to PR may vary significantly among individuals. Many studies were not able to detect significant changes in forced expiratory volume in the first second $\left(\mathrm{FEV}_{1}\right)$, forced vital capacity (FVC), and $\mathrm{FEV}_{1} / \mathrm{FVC}$ values after PR. ${ }^{7-9}$ Thus, a wide range of outcome measures has been described to assess clinically relevant outcomes after PR. The decision to incorporate more sophisticated tests mainly depends on the available resources and the philosophy of each PR center. ${ }^{10}$ Recently, Smargiassi et al have demonstrated the possible role of ultrasound (US) measurement of diaphragm thickness and thickening at the zone of apposition (zapp) at the end of a maximal inspiration might be a useful tool to estimate lung hyperinflation. ${ }^{11}$ Moreover, US analysis of the diaphragmatic excursion has been correlated with bronchial obstruction. ${ }^{12}$ Thus, we hypothesized that US variation of diaphragm mobility and thickness before and after a PR program may represent good markers of the effects of a successful PR program in COPD patients and that these changes may correlate with positive outcome measures postrehabilitation.

Therefore, we aimed to estimate the role of US assessment of diaphragm function in COPD patients undergoing a PR program and in the detection of postrehabilitation outcomes.

\section{Materials and methods Study design and participants}

This prospective observational study was conducted in the Pulmonary Rehabilitation Unit at Policlinico University Hospital, Catania, Italy, between November 2017 and March 2018. Inclusion criteria were as follows: a confirmed diagnosis of COPD according to GOLD criteria, ${ }^{13}$ current or former smoke history of at least 10 pack/years with clinical indication for PR according to British Thoracic Society guidelines ${ }^{14}$ and no exacerbation in the past 12 weeks; patients with pacemaker, unstable angina, recent myocardial infarction, lung cancer, neurological diseases, pleural effusion, interstitial lung diseases, and recent major surgery were excluded.

Forty-seven out of fifty-five consecutive COPD patients (41 males, 87.3\%) were referred for PR during the study period; thirty-seven of those patients met the inclusion criteria and were enrolled in the present study. Twenty-five patients fully completed the 12-week PR program and were considered for data analysis.

\section{Methods}

Eligible patients were assessed for pulmonary function, 6-minute walking test (6MWT), and US assessment of diaphragmatic function and of quadriceps femoris transverse section; all the measurements were done before and after PR. Dyspnea and health status were graded using the modified Medical Research Council (mMRC) dyspnea scale ${ }^{15}$ and COPD Assessment Test (CAT) scale, ${ }^{16}$ respectively; BODE index ${ }^{17}$ and Charlson index ${ }^{18}$ were also used for calculation. Written informed consent was obtained from all participants; Institutional Review Board of Policlinico Hospital, Catania, approved the study (IRB \# 0017237).

\section{Pulmonary function tests}

Pulmonary function tests, spirometry and plethysmography (Medical Graphics, St Paul, MN, USA), were performed following standard protocols, ${ }^{19,20}$ based on reference equations. ${ }^{21}$ Arterial blood gas (ABG) analysis was performed in all patients.

\section{Ultrasonographic measurements}

US measurements were performed using an US machine with probes of 2-6 and 6-15 MHz (Sonoscape A6 e Logic Book GE). Diaphragm US recordings were performed as previously described ${ }^{11}$ by the same investigator (Dr Teresa Augelletti), a physician trained in internal and thoracic echography, who was blinded to patients' PR outcomes. The excursion of right hemi-diaphragm during quiet breathing, at tidal volume $(\mathrm{CV})$, and during deep breathing, at total lung capacity (TLC), starting from normal end-expiratory volume (functional residual capacity, FRC) was measured using a convex probe of $3.5 \mathrm{MHz}$ with $\mathrm{M}$-mode technique, and measurements were obtained at CV and at TLC. We considered normal values as previously defined. ${ }^{22,23}$ Measurements of diaphragm kinetics at the zapp were performed as previously described, ${ }^{24}$ with a probe of 6-15 MHz. Diaphragm thickness was measured at zapp using B-mode US imaging. The zapp was measured at the closest point to the "curtain sign" in which the two hyperecogenic parallel layers of diaphragm were clearly identified in the right intercostal position. We measured the distance of zapp from the skin, its thickness (Szapp), and its length (Lzapp) at different lung volumes: FRC and TLC. It was not possible to evaluate Lzapp at the end of maximal expiration (residual volume, RV) for which a longer linear probe is required. We considered only US measurements obtained at patients' right side for statistical analysis, as left side offers a poor acoustic window in the majority of patients, as in previous studies. ${ }^{25}$ Measurements of quadriceps femoris transverse section were performed as previously described, ${ }^{26}$ taking into account the average of three subsequent measurements. The percentages of change 
$(\Delta \%)$ of US measurements before and after PR for diaphragm zapp were defined as $\Delta$ Lzapp TLC $\%, \Delta$ Lzapp FRC $\%, \Delta$ Szapp $\mathrm{TLC} \%, \Delta$ Szapp FRC $\%$; the $\Delta \%$ for diaphragmatic excursion was defined as $\Delta$ Quiet Breathing $\%$ and $\Delta$ Deep Breathing $\%$. The percentage of change of rectus femoris area was outlined as $\Delta$ Rectus Femoris Area\%.

\section{Pulmonary rehabilitation}

All subjects participated in a 12-week, 3 sessions per week, out-patient-based PR program. The PR training included upper and lower extremity endurance and strength training. ${ }^{1}$ Exercise sessions were conducted for 60 minutes: 10-minute warm-up period, 40-minute aerobic activity, and 10-minute cool-down period. The aerobic activity was composed of the following: 20 minutes of lower limb endurance training by walking on a treadmill or cycling with an exercise intensity target set at a speed of $60 \%$ of the speed of their $6 \mathrm{MWT}$, upper extremity endurance training (arm exercise lifting or stretching elastic bands), and strength training (weight lifting, diagonal arm raises, arm abduction into elevation and reverse, forward flexion, and reverse and straight leg rises). Work rate, $\mathrm{SpO}_{2}$, heart rate, dyspnea scores, and leg fatigue were monitored during the sessions.

\section{Outcome measurements}

We wanted to explore patients' interindividual changes of clinical and US parameters after PR. Moreover, to determine the clinically meaningful responsiveness and effectiveness of PR, we evaluated whether patients achieved the accepted minimal clinically important difference (MCID) for the 6MWT and for the CAT score, after the 12-week PR programs. The MCID considered for 6MWT was $54 \mathrm{~m}$ as previously described. ${ }^{27}$ The MCID for the CAT has not been formally established but, based on its relationship with Saint George Respiratory Questionnaire (SGRQ), where a change of 4 points in the total score has been shown to represent the minimal clinically significant change and that this was equivalent to a decrease of 1.6 points in CAT score, we considered a reduction of at least 2 points in CAT score after PR as the MCID for CAT. ${ }^{28}$ Furthermore, we wanted to explore if the interindividual percentage of change in Lzapp measured by US was able to discriminate between patients who "markedly improved" after PR reaching the MCID at 6MWT and CAT.

\section{Statistical analysis}

Baseline measurements and results were expressed as mean $\pm \mathrm{SD}$ or medians and interquartile ranges for continuous variables and percentage for categorical variables. Intraindividual changes in pulmonary function, dyspnea scores, US measurements, and 6MWD post-PR were assessed by Wilcoxon-signed rank test. We used the nonparametric analysis because the assumption of normality, assessed with Shapiro-Wilk test, was not fulfilled or the presence of outliers was detected for all the variables.

Spearman rank order correlation (rho) was used to estimate the strength of relationships between the intraindividual change of Lzapp at FRC ( $\Delta$ Lzapp $\%)$ and PR outcome expressed as intra-individual change of 6MWD.

Based on the MCID target, at a second stage, we split our patients into two groups:

- Markedly improved: those who improved after PR and reached the minimally clinically important difference of $>54 \mathrm{~m}$ at $6 \mathrm{MWD}$ and a reduction of at least 2 points in CAT score;

- Slightly improved: those who improved after PR but were not able to reach the meaningful cutoff at 6MWD and CAT.

Mann-Whitney $U$-test was employed for comparisons between the groups of "markedly improved" patients (who reached the MCID for 6MWT and CAT) and "slightly improved" patients (who did not achieve the MCID for 6MWT and CAT).

In addition, the receiver operating characteristic (ROC) curves were constructed to assess the ability of $\Delta$ Lzapp $\%$ to discriminate among "markedly improved" and "slightly improved" patients after PR. Youden index, a function of sensitivity and specificity, was calculated to find its maximal value for the determination of an optimal cutoff point of $\Delta$ Lzapp $\%$ after PR in our population. A $P$-value $<0.05$ was considered statistically significant. Statistical analyses were performed using SPSS 15.0.

\section{Results}

The general and baseline characteristics of the study population are shown in Table 1.

All patients were clinically stable and in regular treatment with long-acting beta-2 agonist; 96\% took a long-acting anticholinergic and $52 \%(n=13)$ were treated with inhaled corticosteroids. Patients continued their inhaled drug therapy throughout the study period. All patients attended the entire PR program and completed the 36 sessions (1 hour/session) planned.

All the patients significantly improved after PR in terms of pulmonary function, $\mathrm{ABG}, 6 \mathrm{MWD}, \mathrm{mMRC}$, and CAT score as shown in Table 2; statistically significant improvements after PR were observed also in US parameters of both 
Table I Baseline characteristics of the population

\begin{tabular}{l|l}
\hline Characteristics & $\mathbf{N}=\mathbf{2 5}$ \\
\hline Age (years) & $70.6 \pm 6.5$ \\
BMI $\left(\mathrm{kg} / \mathrm{m}^{2}\right)$ & $25.04 \pm 4.88$ \\
Gender $\mathrm{n}(\%)$ & \\
$\quad$ Female & $2(8.0 \%)$ \\
$\quad$ Male & $23(92.0 \%)$ \\
Smoking history & \\
$\quad$ No smoker & $1(4 \%)$ \\
$\quad$ Current smoker & $7(28 \%)$ \\
Ex-smoker & $17(68 \%)$ \\
GOLD stages & \\
I & $0(0 \%)$ \\
2 & $5(20 \%)$ \\
3 & $14(56 \%)$ \\
4 & $6(24 \%)$ \\
Charlson index & \\
3 & $5(20 \%)$ \\
4 & $8(32 \%)$ \\
5 & $12(48 \%)$ \\
\hline
\end{tabular}

Note: Data are presented as mean \pm SD or $\mathrm{n}(\%)$.

Abbreviations: BMI, body mass index; GOLD, Global Initiative for Chronic Obstructive Lung Disease; Charlson index, Charlson comorbidity index.

diaphragm and quadriceps muscle measures as outlined in Table 3.

We found a moderate positive correlation between the intraindividual percentage of $\Delta \mathrm{Lzapp} \%$ and the change in

Table 2 Patients' characteristics before and after pulmonary rehabilitation

\begin{tabular}{|c|c|c|c|}
\hline $\mathbf{N}=\mathbf{2 5}$ & Pre-PR & Post-PR & $P$-value \\
\hline \multicolumn{4}{|l|}{ Spirometry } \\
\hline FVC\% & $83(73-101)$ & $89(76-102)$ & 0.020 \\
\hline $\mathrm{FEV}_{1} \%$ & $43(34-50)$ & $48(39-55)$ & 0.001 \\
\hline PEF\% & $4 I(40-50)$ & $45(40-5 I)$ & 0.024 \\
\hline $\mathrm{FEV}_{1} / \mathrm{FVC} \%$ & $4 I(34-46)$ & $53(47-63)$ & $<0.001$ \\
\hline VR\% & $132(103-155)$ & $129(100-144)$ & 0.002 \\
\hline TLC\% & $105(97-115)$ & $102(97-112)$ & 0.040 \\
\hline $\mathrm{RV} / \mathrm{TLC} \%$ & $48(38-52)$ & $45(36-50)$ & $<0.01$ \\
\hline \multicolumn{4}{|l|}{ Arterial blood gas } \\
\hline $\mathrm{pH}$ & $7.4 I(7.40-7.42)$ & 7.41 (7.40-7.42) & I \\
\hline $\mathrm{SaO}_{2} \%$ & 94 (9I-95) & 93 (92-95) & 0.008 \\
\hline $\mathrm{PaO}_{2}, \mathrm{mmHg}$ & $65(59-70)$ & 67 (60-7I) & 0.016 \\
\hline $\mathrm{PaCO}_{2}, \mathrm{mmHg}$ & $45(4 \mid-49)$ & $43(40-45)$ & 0.041 \\
\hline 6MWD (m) & $250(150-350)$ & $300(210-400)$ & $<0.001$ \\
\hline CAT & $26(21-34)$ & $24(20-30)$ & $<0.001$ \\
\hline MRC & $4(3-4)$ & $3(2-3)$ & $<0.001$ \\
\hline BODE & $6(4-7)$ & $4(3-6)$ & 0.001 \\
\hline
\end{tabular}

Note: Data are presented as median (25th-75th percentiles).

Abbreviations: PFTs, pulmonary function tests; PR, pulmonary rehabilitation; FVC, forced vital capacity; FEV , forced expiratory volume in I second; PEF, peak forced expiratory flow; $\mathrm{FEV}_{1} / \mathrm{FVC}$, Tiffeneau index; RV, residual volume; TLC, total lung capacity; RV/TLC, Motley index; ABG, arterial blood gas; 6MWD, 6-minute walking distance; CAT, COPD Assessment Test; MRC, Medical Research Council dyspnea score; BODE, BODE index (Body mass index, airflow Obstruction, Dyspnea, and Exercise).
6MWD before and after PR (rho=0.49, $P=0.02$, Figure 1). When grouping our patients in markedly improved (those who improved after PR and reached the MCID of $>54 \mathrm{~m}$ at $6 \mathrm{MWD}$ and a reduction of 2 points of CAT) and slightly improved (those who improved after PR but were not able to reach the meaningful cutoff at 6MWD and CAT, respectively), we found that the intra-individual $\Delta \mathrm{Lzapp} \%$ was significantly higher in the group of "markedly improved" compared to the group of "slightly improved" patients (mean rank=12.03 \pm 2.57 vs $6.88 \pm 4.37$, respectively) ( $P=0.02)$ as shown in Figure 2. The percentages of changes of US measurements between the group of "markedly improved" and "slightly improved" patients at 6MWT are shown in Table 4.

Similarly, we found a statistically significant increase in $\Delta$ Lzapp \% post-PR in the "markedly improved" patients (who reached the MCID for the CAT score) compared to "slightly improved" patients (who did not achieve the MCID goal) $(10.70 \pm 3.20$ vs $6.21 \pm 4.65, P=0.04)$, as shown in Figure 3 . All the percentages of changes of US measurements between the group of "markedly improved" and "slightly improved" patients at CAT score are shown in Table 5.

In addition, we plotted ROC curves to determine $\Delta \mathrm{Lzapp} \%$ with the best sensitivity and specificity to discriminate between patients that "markedly improved" after PR (who reached the threshold of MCID for 6MWT and CAT) and "slightly improved" (who did not achieve the MCID goals). Based on the maximal Youden indexes, the cutoff value able to differentiate between "markedly improved" and "slightly improved" patients at the 6MWT after PR was a $\Delta \mathrm{Lzapp} \%$ of $\geq 10 \%$ with a sensitivity and a specificity of $83 \%$ and $74 \%$, respectively (CI 95\% 0.64-1, $P=0.02$ ). The area under the ROC curve for $\Delta$ Lzapp $\%$ was 0.83 (Figure 4). A cutoff value of $>9 \%$ of $\Delta$ Lzapp $\%$ had a positive predictive value in discriminating MCID for the CAT after PR. Considering this cutoff, the sensitivity and the specificity were $80 \%$ and $62 \%$, respectively (CI 95\% $0.55-0.97, P=0.04$ ), and the area under the ROC curve for $\Delta \mathrm{Lzapp} \%$ was 0.76 (Figure 5).

\section{Discussion}

The results of our study showed that the US assessment of diaphragmatic function was able to accurately identify COPD patients who meaningfully improved after PR.

To our knowledge, this is the first study investigating the role of diaphragm US as a possible outcome of PR in subjects with COPD.

Since the available nonimaging diagnostic tests to assess diaphragmatic function are complex and relatively 
Table 3 Patients' ultrasonographic characteristics before and after pulmonary rehabilitation

\begin{tabular}{l|l|l|l}
\hline $\mathbf{N}=\mathbf{2 5}$ & Pre-PR & Post-PR & P-value \\
\hline Diaphragm zapp (mm) & & & \\
$\quad$ Lzapp TLC & $26(I 8-3 I)$ & $23(19-26)$ & 0.002 \\
$\quad$ Lzapp FRC & $38(32-4 I)$ & $4 I(35-44)$ & $<0.00 I$ \\
$\quad$ Szapp TLC & $5(3-6)$ & $4(3-5)$ & $0.00 I$ \\
$\quad$ Szapp FRC & $4(3-4)$ & $3(3-4)$ & 0.027 \\
Diaphragmatic excursion (mm) & $23(16-27)$ & $27(22-3 I)$ & $<0.00 I$ \\
$\quad$ Quiet breathing & $36(25-53)$ & $50(35-58)$ & $<0.00 I$ \\
$\quad$ Deep breathing & $4(3-4)$ & $4(3-5)$ & $<0.00 I$ \\
Rectus femoris area $\left(\mathrm{m}^{2}\right)$ & & \\
\hline
\end{tabular}

Note: Data are presented as median (25th-75th percentiles).

Abbreviations: PR, pulmonary rehabilitation; zapp, diaphragm zone of apposition; Lzapp, length of diaphragm zone of apposition; Szapp, thickness of diaphragm zone of apposition; TLC, total lung capacity; FRC, functional residual capacity.

invasive, ${ }^{29}$ several functional imaging techniques have been used over time; the most simple method to perform and easy to interpret is the fluoroscopy, ${ }^{30,31}$ which can assess the dome excursion through the sniff test but it involves a significant exposure to ionizing radiation.

Alternatively, chest X-ray and computed tomography (CT) have been used but the possibility of having a dynamic imaging is limited; dynamic magnetic resonance imaging (MRI) has also been described, but it has the limitation of high costs. ${ }^{32}$

Moreover, drawbacks of all these techniques include limited availability and the need for patient transport. Recently, Chun et $a l^{33}$ showed that fluoroscopy is an effective and cost-saving technique for evaluating pulmonary rehabilitation in a small cohort of COPD patients compared with CT

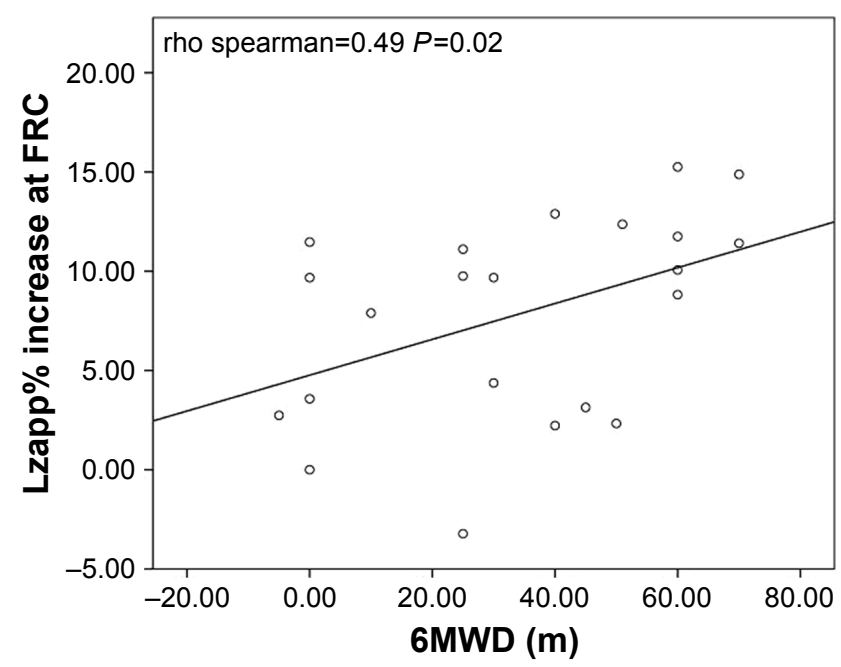

Figure I Correlation between Lzapp and 6MWT.

Note: Spearman rank order correlation between the change (\%) of Lzapp at FRC and the change (delta meters) in 6MWD before and after $P R$ (rho $=0.49, P=0.02$ ).

Abbreviations: Lzapp, diaphragm zone of apposition length; FRC, functional residual capacity; 6MWD, 6-minute walking distance; 6MWT, 6-minute walking test. or MRI, but Houston et al had already clearly stated that US has several advantages over fluoroscopy and it should be considered as the method of choice when studying diaphragm function. ${ }^{34}$

The US assessment of diaphragmatic function has been widely and successfully used to detect the presence of diaphragm dysfunction as a postsurgical complication, ${ }^{35}$ to identify the occurrence of ventilator-induced diaphragm injury, ${ }^{36,37}$ to evaluate diaphragm dome motion ${ }^{25}$ during spontaneous breathing weaning trials, ${ }^{38}$ to quantify the work of breathing ${ }^{39}$ and titrate ventilatory support, ${ }^{39-41}$ and to

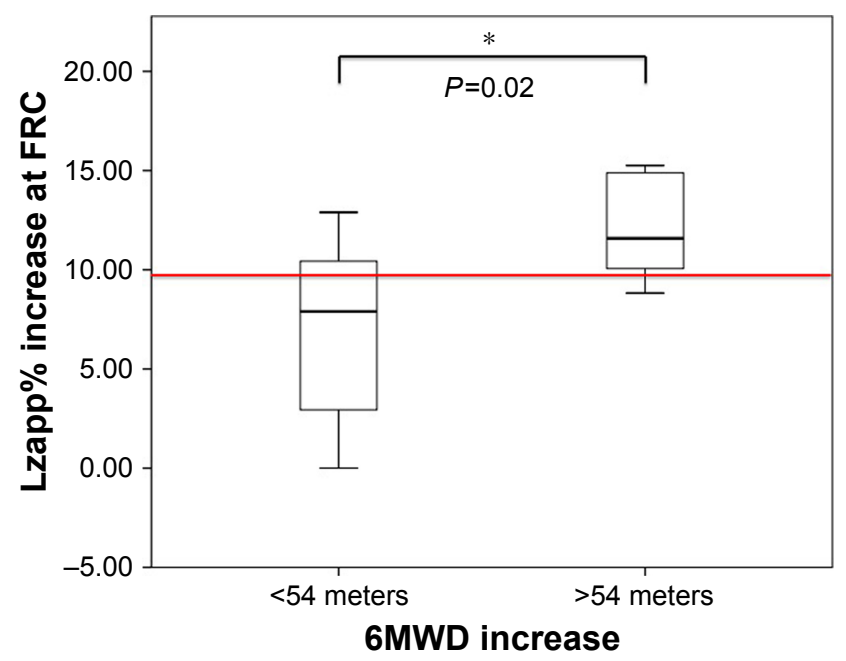

Figure 2 Difference in $\Delta$ Lzapp\% between patients with a minimal clinically significant difference for 6MWD after PR.

Notes: Box plots illustrating the change (\%) of Lzapp at FRC between patients who "slightly improved" (who performed a 6MWD of $<54 \mathrm{~m}$ ) or "markedly improved" (who performed a 6MWD of $>54 \mathrm{~m}$ ) at the 6MWT after PR, $* P<0.05$ (MannWhitney $U$-test). The red line represents the $\Delta$ Lzapp\% cutoff value determined by the receiver operating characteristic (ROC) curve analysis showed in Figure 4.

Abbreviations: Lzapp, length of diaphragm zone of apposition; FRC, functional residual capacity; 6MWD, 6-minute walking distance; 6MWT, 6-minute walking test; $\mathrm{PR}$, pulmonary rehabilitation. 
Table 4 Patients' percentage of change of ultrasonographic measurements after pulmonary rehabilitation between "markedly improved" and "slightly improved" patients based on MCID at 6MWT

\begin{tabular}{|c|c|c|c|}
\hline Ultrasonographic measurements & $\begin{array}{l}\text { 6MWD }>54 \mathrm{~m} \\
\mathrm{~N}=8\end{array}$ & $\begin{array}{l}\text { 6MWD }<54 \mathrm{~m} \\
\mathrm{~N}=17\end{array}$ & $P$-value \\
\hline \multicolumn{4}{|l|}{ Diaphragm zapp } \\
\hline$\Delta$ Lzapp TLC\% & $-15(-26$ to -12$)$ & $-18(-23$ to -9$)$ & 0.791 \\
\hline$\Delta$ Lzapp FRC\% & $12(10-15)$ & $8(3-I I)$ & 0.023 \\
\hline$\Delta$ Szapp TLC\% & $-5(-8$ to -2$)$ & $-5(-10$ to -3$)$ & 0.733 \\
\hline$\Delta$ Szapp FRC\% & $-6(-9$ to 0$)$ & $-7(-11$ to 0$)$ & 0.850 \\
\hline \multicolumn{4}{|l|}{ Diaphragmatic excursion } \\
\hline$\Delta$ Quiet breathing, \% & $5(2-10)$ & $15(3-44)$ & 0.112 \\
\hline$\Delta$ Deep breathing, \% & $6(1-12)$ & $17(5-47)$ & 0.132 \\
\hline$\Delta$ Rectus femoris area, $\%$ & $10(6-15)$ & $8(4-12)$ & 0.850 \\
\hline
\end{tabular}

Note: Data are presented as median (25th-75th percentiles).

Abbreviations: MCID, minimally clinical important difference; PR, pulmonary rehabilitation; zapp, diaphragm zone of apposition; Lzapp, length of diaphragm zone of apposition; Szapp, thickness of diaphragm zone of apposition; TLC, total lung capacity; FRC, functional residual capacity; 6MWD, 6-minute walking distance; 6MWT, 6-minute walking test.

predict extubation success. ${ }^{42}$ This technique has been studied in COPD patients, showing a reduction in diaphragmatic excursion and thickening in the subset of patients with more pronounced air-trapping ${ }^{11,43,44}$ and to establish diaphragmatic dysfunction, ${ }^{45}$ but no studies have explored the use of this technique in the PR settings.

The first remarkable finding of this study is that the sonographic evaluation of the diaphragm is able to document a significant change of diaphragmatic excursion after PR in COPD patients. Our study also strengthened the results of previous studies ${ }^{26,46}$ about the utility of ultrasound

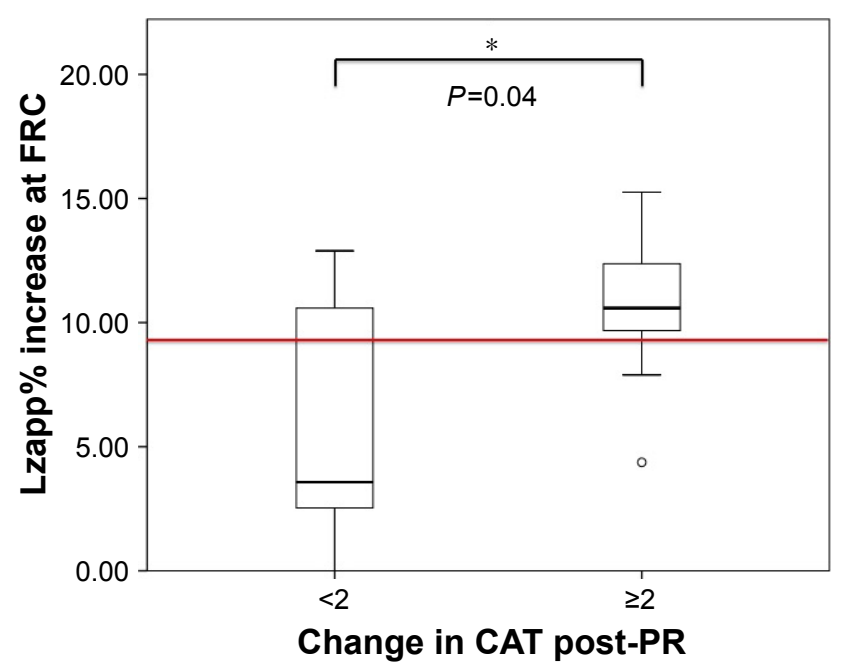

Figure 3 Difference in $\Delta$ Lzapp\% between patients with a minimal clinically significant difference for CAT after PR.

Notes: Box plots illustrating the change (\%) of Lzapp at FRC between patients "slightly improved" (who achieved a $<2$ points reduction of CAT score) or "markedly improved" (who achieved $\geq 2$ points reduction in CAT score), $* P<0.05$ (MannWhitney $U$-test). The red line represents the $\Delta$ Lzapp\% cutoff value determined by the receiver operating characteristic (ROC) curve analysis showed in Figure 5.

Abbreviations: Lzapp, length of diaphragm zone of apposition; FRC, functional residual capacity; CAT, COPD Assessment Test; PR, pulmonary rehabilitation. measurements of the rectus femoris area as a noninvasive tool of measuring muscle mass change in patients who underwent PR.

The portability and wide availability of US make sonographic evaluation of both diaphragm and quadriceps femoris ideally suited for a routine incorporation into the PR assessment, to complement a more complete appraisal of COPD patients undergoing PR, to measure individual's progresses, to potentially tailor PR program for each patient, and to evaluate its outcomes. Indeed, the US technique does not require any special effort, coordination, or cooperation, and therefore can be easily used also in older and more severe patients. Moreover, we can speculate that US diaphragmatic assessment may help in identifying the subpopulation of COPD patients with diaphragm muscle dysfunction and consequent ventilatory mechanics alterations that may expose patients at a major risk of reexacerbation due to a low maximum diaphragm excursion $;{ }^{47}$ therefore, this technique can be helpful in phenotyping subgroups of COPD patients, identifying those who are potentially more frail and probably at higher risk of exacerbations and it might be even used as a criterion for assigning a rehabilitation priority in the waiting list for the inhospital PR program. Furthermore, US is an accurate, reproducible, and relatively easy to learn technique that needs little learning curve; therefore, even physiotherapists could use this tool in their clinical decisionmaking processes before and after PR, as already reported in the literature. ${ }^{48}$

The second important finding of our study is that the US assessment of diaphragmatic function may accurately predict the response to PR. In fact, in our study the intraindividual $\Delta$ Lzapp $\%$ was significantly higher in patients who markedly 
Table 5 Patients' percentage of change of ultrasonographic measurements after pulmonary rehabilitation between "markedly improved" and "slightly improved" patients based on MCID at CAT

\begin{tabular}{|c|c|c|c|}
\hline Ultrasonographic measurements & $\begin{array}{l}\text { CAT } \geq 2 \\
N=14\end{array}$ & $\begin{array}{l}\text { CAT }<2 \\
\mathbf{N}=\mathbf{I} \mathbf{I}\end{array}$ & $P$-value \\
\hline \multicolumn{4}{|l|}{ Diaphragm Zapp } \\
\hline$\Delta$ Lzapp TLC\% & $-18(-26$ to -15$)$ & $-13(-23$ to -2$)$ & 0.197 \\
\hline$\Delta$ Lzapp FRC\% & II (I0-12) & $4(2-11)$ & 0.043 \\
\hline$\Delta$ Szapp TLC\% & $-4(-8$ to -3$)$ & $-6(-10$ to -2$)$ & 0.863 \\
\hline$\Delta$ Szapp FRC\% & $-5(-10$ to 0$)$ & $-8(-12$ to 0$)$ & 0.756 \\
\hline \multicolumn{4}{|l|}{ Diaphragmatic excursion } \\
\hline$\Delta$ Quiet breathing, $\%$ & $10(1-15)$ & $38(3-60)$ & 0.180 \\
\hline$\Delta$ Deep breathing, $\%$ & $14(6-31)$ & $17(3-47)$ & 0.913 \\
\hline$\Delta$ Rectus femoris area, $\%$ & $8(3-17)$ & $8(4-12)$ & 1 \\
\hline
\end{tabular}

Note: Data are presented as median (25th-75th percentiles).

Abbreviations: MCID, minimally clinical important difference; PR, pulmonary rehabilitation; Zapp, diaphragm zone of apposition; Lzapp, length of diaphragm zone of apposition; Szapp, thickness of diaphragm zone of apposition; TLC, total lung capacity; FRC, functional residual capacity; CAT, COPD Assessment Test.

improved after PR in terms of reaching a meaningful target (MCID) at 6MWT and CAT score. Moreover, our study showed that a cut-off value of $>9 \% \Delta$ Lzapp $\%$ showed a positive predictive value in discriminating clinically meaningful improvement both in the 6MWD and CAT scores of COPD patients after PR. Therefore, these findings should remind clinicians about the importance of diaphragm evaluation using thoracic US in daily clinical practice and that the

\section{ROC curve for Lzapp\% increase at FRC}

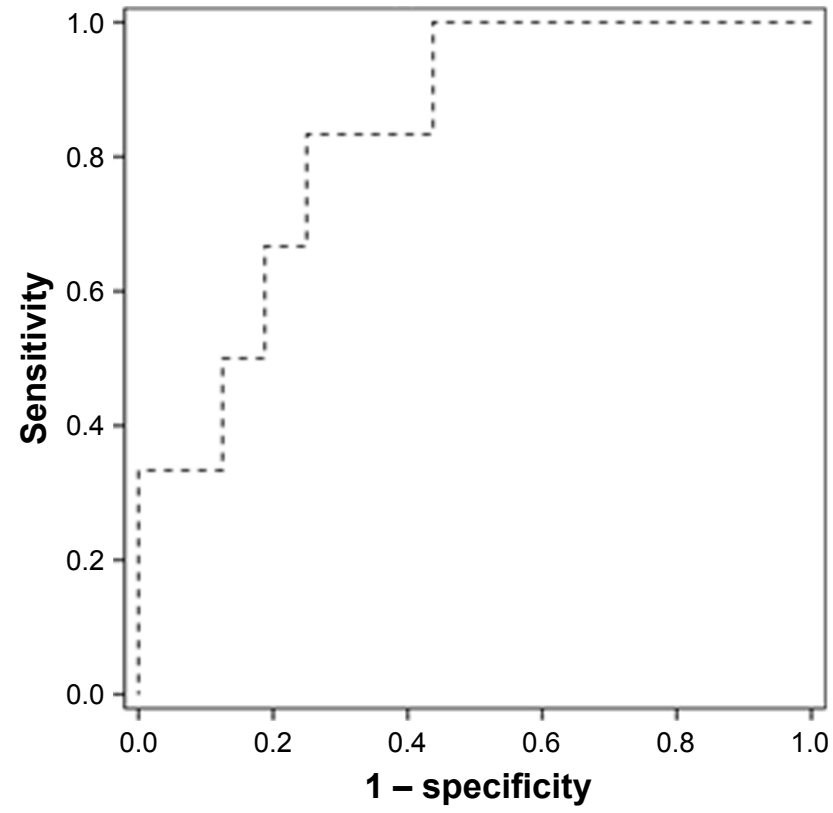

Figure 4 Receiver operating characteristic (ROC) curve for $\Delta$ Lzapp\% in relation to $6 \mathrm{MWD}$.

Note: ROC curves estimate the ability of Lzapp change (as percentage of baseline) to predict a significant improvement in 6MWD after PR ( $A \cup C=0.83$, cutoff $\geq 10 \%$, sensitivity $=83 \%$, specificity $=74 \%$ ).

Abbreviations: AUC, area under the curve; Lzapp, length of diaphragm zone of apposition; FRC, functional residual capacity; 6MWD, 6-minute walking distance; 6MWT, 6-minute walking test; PR, pulmonary rehabilitation. identification of this percentage of change after PR may contribute in phenotyping COPD patients with a fast and non-invasive technique.

Last but not least, a sonographic study can demonstrate to patients the improvement of the muscle function with a simple visual image; therefore, we can speculate that this might be used as a coping strategy for patients, feeling involved in the management of their disease, and hopefully improving adherence to

\section{ROC curve for Lzapp\% increase at FRC}

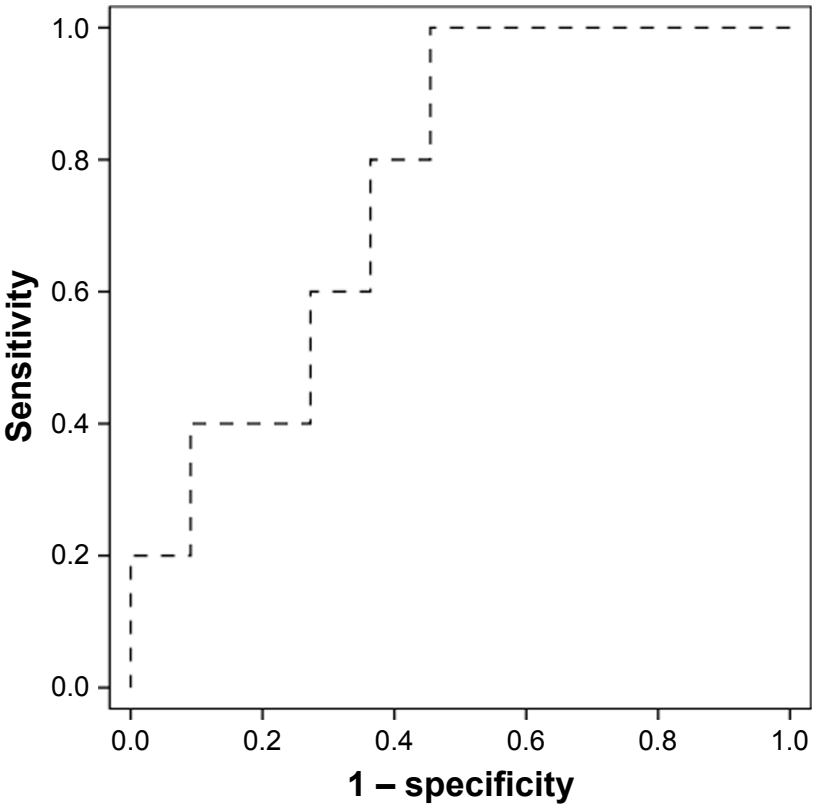

Figure 5 Receiver operating characteristic (ROC) curve for $\Delta$ Lzapp\% in relation to CAT.

Note: ROC curves estimate the ability of Lzapp change (as percentage of baseline) to predict a significant improvement in CAT after PR (AUC $=0.76$, cutoff $>9 \%$, sensitivity $=80 \%$, specificity $=62 \%$ ).

Abbreviations: AUC, area under the curve; Lzapp, length of diaphragm zone of apposition; FRC, functional residual capacity; CAT, COPD Assessment Test; PR, pulmonary rehabilitation. 
PR program. There are several limitations to the present study that should be mentioned. First, the relatively small number of patients might have influenced the results; second, we did not measure diaphragmatic thickness during inspiration that has been used as an indirect measurement of muscle fiber contraction; even though several different US techniques have been described so far, at the moment, no standardized approaches are recommended for a comprehensive study of diaphragm function. ${ }^{49}$ Third, health-related quality of life measurements such as SGRQ were not recorded for all patients and therefore not suitable for data analysis. Moreover, we did not measure the maximal static inspiratory pressure and maximal static expiratory pressure. Finally, we have to consider that US can be operator dependent; in the present study, US data recordings were reported only by one physician, qualified in using ultrasonography in daily practice; therefore, the interobserver variability could not be evaluated. Nevertheless, we really believe that our results have important clinical implications that can still be generalized in the hospital-based settings.

In conclusion, our study supports the routine use of US diaphragmatic assessment before and after PR as an additional tool for the evaluation of clinical effects of PR in COPD patients. It provides a rapid, reliable, noninvasive and relatively easy-to-use approach that allows repeated measures and does not require patient's effort or coordination, and it should be used in combination with other exams to assess PR outcomes.

\section{Acknowledgments}

The study was presented as an abstract at the ERS International Congress 2018 held in Paris, September 15-19, 2018. No potential conflicts of interest exist with any companies or organizations whose products or services may be discussed in this article. Support was provided solely from institutional and department resources.

\section{Author contributions}

$\mathrm{CC}$ is the guarantor of the content of the manuscript, including the data and analysis, and certifies that the methods, data, and analysis set forth in this paper are truthful and accurate. TA has performed diaphragmatic ultrasound recordings to our patient population. All authors made substantial contributions to the conception and design of the analysis and interpretation of data. All authors contributed toward data analysis, drafting and revision of the paper, and agreed to be accountable for all aspects of the work. All authors provided their final approval to the version to be published. The authors are accountable for the accuracy and integrity of this work.

\section{Disclosure}

The authors report no conflicts of interest in this work.

\section{References}

1. Spruit MA, Singh SJ, Garvey C, et al. An official American Thoracic Society/European Respiratory Society statement: key concepts and advances in pulmonary rehabilitation. Am J Respir Crit Care Med. 2013; 188(8):e13-e64.

2. Casaburi R, Porszasz J, Burns MR, Carithers ER, Chang RS, Cooper CB. Physiologic benefits of exercise training in rehabilitation of patients with severe chronic obstructive pulmonary disease. Am J Respir Crit Care Med. 1997;155(5):1541-1551.

3. Sala E, Roca J, Marrades RM, et al. Effects of endurance training on skeletal muscle bioenergetics in chronic obstructive pulmonary disease. Am J Respir Crit Care Med. 1999;159(6):1726-1734.

4. Gigliotti F, Coli C, Bianchi R, et al. Exercise training improves exertional dyspnea in patients with COPD: evidence of the role of mechanical factors. Chest. 2003;123(6):1794-1802.

5. Takigawa N, Tada A, Soda R, et al. Comprehensive pulmonary rehabilitation according to severity of COPD. Respir Med. 2007;101(2): 326-332.

6. Vogiatzis I, Zakynthinos S. The physiological basis of rehabilitation in chronic heart and lung disease. J Appl Physiol. 2013;115(1): $16-21$.

7. Niederman MS, Clemente PH, Fein AM, et al. Benefits of a multidisciplinary pulmonary rehabilitation program. Improvements are independent of lung function. Chest. 1991;99(4):798-804.

8. Vogiatzis I, Williamson AF, Miles J, Taylor IK. Physiological response to moderate exercise workloads in a pulmonary rehabilitation program in patients with varying degrees of airflow obstruction. Chest. 1999;116(5):1200-1207.

9. Karapolat H, Atasever A, Atamaz F, Kirazli Y, Elmas F, Erdinç E. Do the benefits gained using a short-term pulmonary rehabilitation program remain in COPD patients after participation? Lung. 2007;185(4): 221-225.

10. Singh S. Approaches to outcome assessment in pulmonary rehabilitation. Clin Chest Med. 2014;35(2):353-361.

11. Smargiassi A, Inchingolo R, Tagliaboschi L, di Marco Berardino A, Valente S, Corbo GM. Ultrasonographic assessment of the diaphragm in chronic obstructive pulmonary disease patients: relationships with pulmonary function and the influence of body composition - a pilot study. Respiration. 2014;87(5):364-371.

12. Zanforlin A, Smargiassi A, Inchingolo R, di Marco Berardino A, Valente S, Ramazzina E. Ultrasound analysis of diaphragm kinetics and the diagnosis of airway obstruction: the role of the M-mode index of obstruction. Ultrasound Med Biol. 2014;40(6):1065-1071.

13. Vestbo J, Hurd SS, Agustí AG, et al. Global strategy for the diagnosis, management, and prevention of chronic obstructive pulmonary disease: GOLD executive summary. Am J Respir Crit Care Med. 2013;187(4):347-365.

14. Bolton CE, Bevan-Smith EF, Blakey JD, et al. British Thoracic Society guideline on pulmonary rehabilitation in adults. Thorax. 2013; 68(Suppl 2):ii1-ii30.

15. Bestall JC, Paul EA, Garrod R, Garnham R, Jones PW, Wedzicha JA. Usefulness of the Medical Research Council (MRC) dyspnoea scale as a measure of disability in patients with chronic obstructive pulmonary disease. Thorax. 1999;54(7):581-586.

16. Jones PW, Harding G, Berry P, Wiklund I, Chen WH, Kline Leidy N. Development and first validation of the COPD Assessment Test. Eur Respir J. 2009;34(3):648-654.

17. Celli BR, Cote CG, Marin JM, et al. The body-mass index, airflow obstruction, dyspnea, and exercise capacity index in chronic obstructive pulmonary disease. N Engl J Med. 2004;350(10):1005-1012.

18. Charlson M, Szatrowski TP, Peterson J, Gold J. Validation of a combined comorbidity index. J Clin Epidemiol. 1994;47(11):1245-1251.

19. Spirometry Sof. Update. American Thoracic Society. Am J Respir Crit Care Med. 19941995;152(3):1107-1136. 
20. Miller MR, Crapo R, Hankinson J, et al. General considerations for lung function testing. Eur Respir J. 2005;26(1):153-161.

21. Knudson RJ, Slatin RC, Lebowitz MD, Burrows B. The maximal expiratory flow-volume curve. Normal standards, variability, and effects of age. Am Rev Respir Dis. 1976;113(5):587-600.

22. Boussuges A, Gole Y, Blanc P. Diaphragmatic motion studied by m-mode ultrasonography: methods, reproducibility, and normal values. Chest. 2009;135(2):391-400.

23. Toledo NS, Kodaira SK, Massarollo PC, et al. Left hemidiaphragmatic mobility: assessment with ultrasonographic measurement of the craniocaudal displacement of the splenic hilum and the inferior pole of the spleen. J Ultrasound Med. 2006;25(1):41-49.

24. Gorman RB, Mckenzie DK, Pride NB, Tolman JF, Gandevia SC. Diaphragm length during tidal breathing in patients with chronic obstructive pulmonary disease. Am J Respir Crit Care Med. 2002;166(11): 1461-1469.

25. Tobin MJ, Laghi F, Brochard L. Role of the respiratory muscles in acute respiratory failure of COPD: lessons from weaning failure. J Appl Physiol. 2009;107(3):962-970.

26. Seymour JM, Ward K, Sidhu PS, et al. Ultrasound measurement of rectus femoris cross-sectional area and the relationship with quadriceps strength in COPD. Thorax. 2009;64(5):418-423.

27. Redelmeier DA, Bayoumi AM, Goldstein RS, Guyatt GH. Interpreting small differences in functional status: the Six Minute Walk test in chronic lung disease patients. Am J Respir Crit Care Med. 1997;155(4): 1278-1282.

28. Kon SS, Dilaver D, Mittal M, et al. The Clinical COPD Questionnaire: response to pulmonary rehabilitation and minimal clinically important difference. Thorax. 2014;69(9):793-798.

29. Similowski T, Yan S, Gauthier AP, Macklem PT, Bellemare F. Contractile properties of the human diaphragm during chronic hyperinflation. N Engl J Med. 1991;325(13):917-923.

30. Alexander C. Diaphragm movements and the diagnosis of diaphragmatic paralysis. Clin Radiol. 1966;17(1):79-83.

31. Chavhan GB, Babyn PS, Cohen RA, Langer JC. Multimodality imaging of the pediatric diaphragm: anatomy and pathologic conditions. Radiographics. 2010;30(7):1797-1817.

32. Nason LK, Walker CM, Mcneeley MF, Burivong W, Fligner CL, Godwin JD. Imaging of the diaphragm: anatomy and function. Radiographics. 2012;32(2):E51-E70.

33. Chun EM, Han SJ, Modi HN. Analysis of diaphragmatic movement before and after pulmonary rehabilitation using fluoroscopy imaging in patients with COPD. Int J Chron Obstruct Pulmon Dis. 2015;10:193-199.

34. Houston JG, Fleet M, Cowan MD, Mcmillan NC. Comparison of ultrasound with fluoroscopy in the assessment of suspected hemidiaphragmatic movement abnormality. Clin Radiol. 1995;50(2):95-98.

35. Lerolle N, Guérot E, Dimassi S, et al. Ultrasonographic diagnostic criterion for severe diaphragmatic dysfunction after cardiac surgery. Chest. 2009;135(2):401-407.
36. Vassilakopoulos T, Petrof BJ, Dysfunction V-Induceddiaphragmatic. Ventilator-induced diaphragmatic dysfunction. Am J Respir Crit Care Med. 2004;169(3):336-341.

37. International consensus conferences in intensive care medicine. Ventilator-associated lung injury in ARDS. American Thoracic Society, European Society of Intensive Care Medicine, Societé de Réanimation Langue Française. Intensive Care Med. 1999;25(12):1444-1452.

38. Llamas-Álvarez AM, Tenza-Lozano EM, Latour-Pérez J. Diaphragm and lung ultrasound to predict weaning outcome: systematic review and meta-analysis. Chest. 2017;152(6):1140-1150.

39. Vivier E, Mekontso Dessap A, Dimassi S, et al. Diaphragm ultrasonography to estimate the work of breathing during non-invasive ventilation. Intensive Care Med. 2012;38(5):796-803.

40. Umbrello M, Formenti P, Longhi D, et al. Diaphragm ultrasound as indicator of respiratory effort in critically ill patients undergoing assisted mechanical ventilation: a pilot clinical study. Crit Care. 2015; 19:161.

41. Goligher EC, Laghi F, Detsky ME, et al. Measuring diaphragm thickness with ultrasound in mechanically ventilated patients: feasibility, reproducibility and validity. Intensive Care Med. 2015;41(4):734.

42. Dinino E, Gartman EJ, Sethi JM, Mccool FD. Diaphragm ultrasound as a predictor of successful extubation from mechanical ventilation. Thorax. 2014;69(5):431-435.

43. Paulin E, Yamaguti WP, Chammas MC, et al. Influence of diaphragmatic mobility on exercise tolerance and dyspnea in patients with COPD Respir Med. 2007;101(10):2113-2118.

44. dos Santos Yamaguti WP, Paulin E, Shibao S, et al. Air trapping: the major factor limiting diaphragm mobility in chronic obstructive pulmonary disease patients. Respirology. 2008;13(1):138-144.

45. Scheibe N, Sosnowski N, Pinkhasik A, Vonderbank S, Bastian A. Sonographic evaluation of diaphragmatic dysfunction in COPD patients. Int J Chron Obstruct Pulmon Dis. 2015;10:1925-1930.

46. Ozmen I, Yildirim E, Özçinar F, Öztürk M. The effect the pulmonary rehabilitation in rectus femoris cross-sectional area increase and exercise capacity in patients with chronic obstructive pulmonary disease. Eur Res J. 2015;46(S59):PA747.

47. Antenora F, Fantini R, Iattoni A, et al. Prevalence and outcomes of diaphragmatic dysfunction assessed by ultrasound technology during acute exacerbation of COPD: a pilot study. Respirology. 2017;22(2): 338-344.

48. Le Neindre A, Mongodi S, Philippart F, Bouhemad B. Thoracic ultrasound: potential new tool for physiotherapists in respiratory management. A narrative review. J Crit Care. 2016;31(1):101-109.

49. Sferrazza Papa GF, Pellegrino GM, di Marco F, et al. A review of the ultrasound assessment of diaphragmatic function in clinical practice. Respiration. 2016;91(5):403-411.
International Journal of COPD

\section{Publish your work in this journal}

The International Journal of COPD is an international, peer-reviewed journal of therapeutics and pharmacology focusing on concise rapid reporting of clinical studies and reviews in COPD. Special focus is given to the pathophysiological processes underlying the disease, intervention programs, patient focused education, and self management protocols.

\section{Dovepress}

This journal is indexed on PubMed Central, MedLine and CAS. The manuscript management system is completely online and includes a very quick and fair peer-review system, which is all easy to use. Visit http://www.dovepress.com/testimonials.php to read real quotes from published authors. 